Int. J. Electrochem. Sci., 15 (2020) $3469-3478$

International Journal of

ELECTROCHEMICAL

SCIENCE

WWW.electrochemsci.org

\title{
Controllable Synthesis of Silver Nanoparticles by the Pulsed Electrochemical Deposition in a Forced circulation Reactor
}

Di Yin ${ }^{1}$, Yiyang Liu ${ }^{1}$, Peng Chen ${ }^{1}$, Guangyuan Meng ${ }^{1}$, Guangtuan Huang ${ }^{1}$, Lankun Cai ${ }^{1}$, Lehua Zhang ${ }^{1,2, *}$

${ }^{1}$ State Environmental Protection Key Laboratory of Environmental Risk Assessment and Control on Chemical Process, School of Resources and Environmental Engineering, East China University of Science and Technology, Shanghai 200237, P. R. China.

${ }^{2}$ Shanghai Institute of Pollution Control and Ecological Security, Shanghai 200092, P. R. China.

*E-mail: lezhanghua@163.com

doi: $10.20964 / 2020.04 .57$

Received: 26 December 2019 / Accepted: 210 February 2020 / Published: 10 March 2020

A novel pulsed electrochemical system was constructed to synthesize size-controllable spherical AgNPs in the aqueous phase. The circulation system was found to greatly reduce silver deposition rate, thereby making well-dispersed AgNPs colloids to be synthesized very convenient without ultrasonication and string system. Moreover, the particle size of AgNPs were controlled by the experimental parameters (ontime, off-time, and peak current) to improve homogeneity of the prepared AgNPs. The smallest sized AgNPs with a size of $14.9 \pm 4 \mathrm{~nm}$ were obtained with an on-time, off-time, and peak current of $0.8 \mathrm{~ms}$, $0.3 \mathrm{~ms}$, and $0.2 \mathrm{~A}$, respectively. In addition, a clear linear positive correlation between the size of silver nanoparticles and the peak current was found in this system.

Keywords: Silver nanoparticles; Controllable synthesis; Pulsed electrochemical system

\section{$\underline{\text { FULL TEXT }}$}

(C) 2020 The Authors. Published by ESG (www.electrochemsci.org). This article is an open access article distributed under the terms and conditions of the Creative Commons Attribution license (http://creativecommons.org/licenses/by/4.0/). 